\title{
Effectiveness of eHealth Interventions in Improving Medication Adherence for Patients With Chronic Obstructive Pulmonary Disease or Asthma: Systematic Review
}

Mieke H J Schulte $^{1 *}$, PhD; Jiska J Aardoom ${ }^{1,2,3^{*}}, \mathrm{PhD}$; Lisa Loheide-Niesmann ${ }^{1,4}$, MSc; Leonie L L Verstraete $^{1}$, MSc; Hans C Ossebaard ${ }^{5}$, PhD; Heleen Riper ${ }^{1,6,7}$, Prof Dr

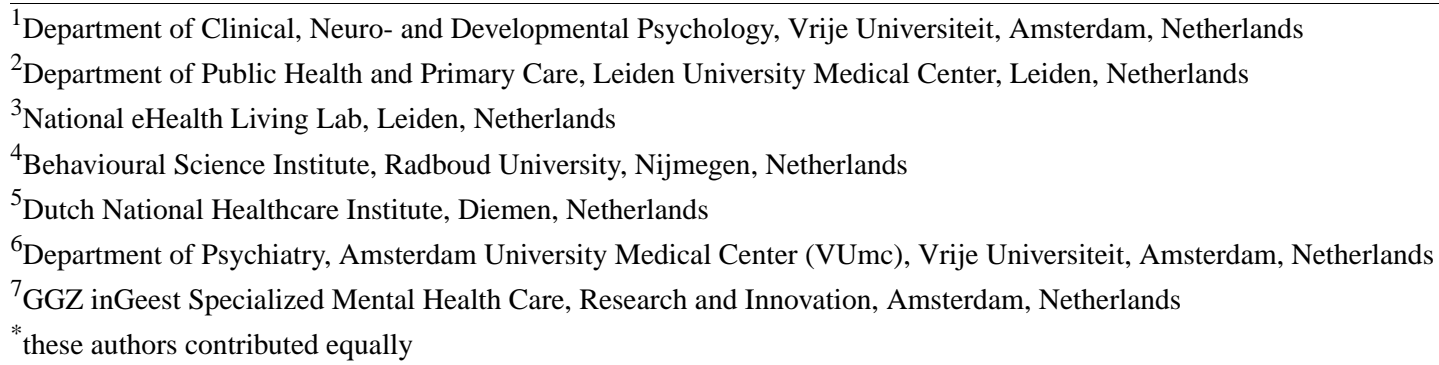

Corresponding Author:

Heleen Riper, Prof Dr

Department of Clinical, Neuro- and Developmental Psychology

Vrije Universiteit

Medical Faculty

Van der Boechorststraat 7

Amsterdam, 1081 BT

Netherlands

Phone: 31205982619

Email: h.riper@vu.nl

\section{Abstract}

Background: Poor treatment adherence in patients with chronic obstructive pulmonary disease (COPD) or asthma is a global public health concern with severe consequences in terms of patient health and societal costs. A potentially promising tool for addressing poor compliance is eHealth.

Objective: This review investigates the effects of eHealth interventions on medication adherence in patients with COPD or asthma.

Methods: A systematic literature search was conducted in the databases of Cochrane Library, PsycINFO, PubMed, and Embase for studies with publication dates between January 1, 2000, and October 29, 2020. We selected randomized controlled trials targeting adult patients with COPD or asthma, which evaluated the effectiveness of an eHealth intervention on medication adherence. The risk of bias in the included studies was examined using the Cochrane Collaboration's risk of bias tool. The results were narratively reviewed.

Results: In total, six studies focusing on COPD and seven focusing on asthma were analyzed. Interventions were mostly internet-based or telephone-based, and could entail telemonitoring of symptoms and medication adherence, education, counseling, consultations, and self-support modules. Control groups mostly comprised usual care conditions, whereas a small number of studies used a face-to-face intervention or waiting list as the control condition. For COPD, the majority of eHealth interventions were investigated as an add-on to usual care (5/6 studies), whereas for asthma the majority of interventions were investigated as a standalone intervention (5/7 studies). Regarding eHealth interventions targeting medication adherence for COPD, two studies reported nonsignificant effects, one study found a significant effect in comparison to usual care, and three reported mixed results. Of the seven studies that investigated eHealth interventions targeting medication adherence in asthma, three studies found significant effects, two reported nonsignificant effects, and two reported mixed effects.

Conclusions: The mixed results on the effectiveness of eHealth interventions in improving treatment adherence for asthma and COPD are presumably related to the type, context, and intensity of the interventions, as well as to differences in the 
operationalization and measurement of adherence outcomes. Much remains to be learned about the potential of eHealth to optimize treatment adherence in COPD and asthma.

(J Med Internet Res 2021;23(7):e29475) doi: 10.2196/29475

\section{KEYWORDS}

chronic obstructive pulmonary disease; asthma; medication adherence; exercise adherence; treatment adherence; eHealth; systematic review; COPD; adherence; exercise; treatment; review

\section{Introduction}

With a global prevalence of over 299 million people living with chronic obstructive pulmonary disease (COPD) and almost 273 million people living with asthma in 2017 [1], COPD and asthma are common chronic lung diseases. They are a worldwide public health concern and they increasingly affect the lives of patients due to climate change and pollution [2]. The clinical and economic burden of asthma and COPD have been widely established [3]. Both these respiratory diseases are typically treated and managed with drug therapies, often in the form of daily inhaled medication. Full adherence is important for optimal management and treatment of COPD and asthma [4-6]. This is especially the case when patients become more vulnerable, such as during environmental disruptions or the current COVID-19 pandemic [7].

Unfortunately, adherence to treatment regimens for COPD and asthma is often poor. Adherence to inhaled corticosteroids (ICS) in adult patients with asthma is estimated to range from $22 \%$ to $63 \%$ [8]. Medication adherence in patients with COPD reportedly ranges from $0.3 \%$ to $68 \%$, depending on the type and combination of medications [9]. Adherence is a complex, multifaceted concept, including many potential contributing factors, which can be medication-related (eg, side effects) or patient-related (eg, forgetfulness, medication beliefs) [10]. Poor adherence can severely impact patients' health outcomes, with consequences including an increased risk of mortality and exacerbations, as well as diminished disease control and quality of life [5]. Poor adherence has furthermore been associated with higher health care utilization and costs $[5,6]$. Therefore, there is an urgent need for interventions that can improve treatment adherence in individuals with COPD or asthma.

A recent Cochrane review comprising 28 randomized controlled trials reported positive effects of various interventions to improve adherence to ICS in asthma in comparison to usual care [11]. After approximately 71 weeks of follow-up, a $20 \%$ improvement was achieved for people who were given education about adherence (20 trials) or who were provided with electronic monitoring or reminders to use their inhaler (11 trials). Another review investigated the effect of interventions to improve medication adherence in COPD [12]. Overall, five of the seven studies reported significant improvements in adherence. Effective strategies involved brief counseling, monitoring, and feedback on adherence through electronic medication delivery devices, as well as multicomponent interventions including education, self-management, motivational interviewing, and extra support (eg, clinic visits, phone calls) by health care professionals. Whether such strategies produced effects of similar magnitudes remains unclear.
Increasingly, eHealth is being used in the provision of health care services such as patient communication, monitoring, and education. In general, eHealth can be an effective tool to address poor treatment adherence in patients with chronic diseases, as indicated by the results of numerous studies focusing on different target populations [13-17]. However, to our knowledge, no systematic review or meta-analysis has yet been performed investigating the effects of eHealth interventions on adherence specifically for patients with COPD and only limited research has focused on youth or adult asthma populations. Bonini [18] conducted a systematic review of the literature published in 2016 that assessed the effects of eHealth on asthma management, incorporating multiple components including medication adherence in children and adults. The findings suggested an overall beneficial effect of eHealth on asthma control and management, whereby eHealth included mobile health systems (mHealth), telemedicine, electronic health records, and digital app interventions. A recent meta-analysis investigated the effect of eHealth on ICS adherence in patients with asthma (including both children and adults), comprising 15 randomized controlled trials with a total of 13,907 participants. Compared with usual care, a small but significant overall effect of eHealth interventions was observed. In addition, a pooled analysis of four studies provided evidence for the superiority of mHealth interventions such as SMS text messages and audiovisual reminders as compared to usual care [19].

The aim of our study was to systematically review the effectiveness of eHealth interventions in improving medication adherence in adult patients with COPD or asthma. In this review, the results were presented separately for asthma and COPD in order to enable investigation of potential differences between the diseases, as well as to allow for potential nuance in terms of the effectiveness of specific eHealth interventions for the two diseases separately.

\section{Methods}

No review protocol was made beforehand and the review was not registered in any database or registry. The PRISMA (Preferred Reporting Items for Systematic Reviews and Meta-Analyses) checklist can be found in Multimedia Appendix 1.

\section{Search Strategy}

Our search strategy was part of a broader search performed in a research project on the role of eHealth in treatment adherence in chronic lung disease, including obstructive sleep apnea (OSA), asthma, and COPD. The results regarding OSA have been published elsewhere [20]. The search was conducted in the electronic databases of the Cochrane Library (Wiley), 
PsycINFO (EBSCO), PubMed, and Embase. The search results were limited to available full-text articles in English or Dutch with publication dates from January 1, 2000, to October 29. 2020. Numerous terms related to eHealth technology, patient adherence, and the target populations (asthma, COPD) were combined, using both free-text and index terms (for the full search string, see Multimedia Appendix 2). In addition, reference lists of the included studies, as well as relevant systematic reviews, were checked for potentially relevant additional studies.

\section{Study Selection and Data Extraction}

Inclusion criteria were as follows: (1) The target population comprised patients aged $\geq 18$ years with COPD or asthma. (2) One or more main component(s) of the intervention were delivered by eHealth technology, or an eHealth component was investigated as an add-on intervention to usual care. The criteria to qualify as an eHealth intervention were that (A) the intervention was delivered via information and communications technology such as telephone calls, telemedicine (eg, videoconferencing), websites, smartphone apps, or SMS text messages; and (B) the intervention was delivered independently of time and place (eg, videos delivered in face-to-face sessions were not considered eligible). (3) Intervention effects were compared to a control group, with exclusion of control conditions containing the same eHealth component as the experimental condition. (4) Outcomes were assessed in terms of at least one quantitative measure of adherence to the medical treatment - that is, to oral or inhaler medication. (5) Adherence measures were compared statistically between study conditions. (6) The study design was a randomized controlled trial.

All titles and abstracts were independently screened by two reviewers (JA and LL: January 1, 2000, through March 20, 2018; MS and LV: March 21, 2018, through October 29, 2020). Subsequently, the full-text articles of the selected papers were screened to determine eligibility for this review. Covidence software was used to manage the screening process and the risk-of-bias assessments. Data on study reference, design, population, interventions, outcomes, and results were extracted by means of a data extraction form in an Excel spreadsheet by JA (January 1, 2000, through March 20, 2018) and MS (March 21, 2018, through October 29, 2020).

\section{Quality Assessment}

The Cochrane Collaboration's risk-of-bias tool [21] was used to assess the quality of all included studies. Two reviewers (JA and LL or MS and LV, depending on publication date; see above) independently evaluated the following dimensions of risk of bias: (1) adequacy of random sequence generation, (2) adequacy of concealment of allocation sequence to personnel, (3) blinding of study participants and personnel, (4) blinding of outcome assessors, (5) adequacy of handling of incomplete outcome data, and (6) selective outcome reporting. Each study was rated per dimension as "low risk," "high risk," or "unclear risk." Disagreements between reviewers were resolved by discussion.

\section{Data Analysis}

Due to the limited number of available studies and the heterogeneity of the studies in terms of designs and characteristics, as well as the assessments and operationalizations of medication adherence, the results were narratively reviewed and no meta-analysis has been performed.

\section{Results}

\section{Search and Screening}

Figure 1 depicts the PRISMA flow diagram of study identification and selection. The pooled systematic search resulted in a total of 6447 potentially relevant articles covering COPD or asthma. After removal of 2520 duplicates, a total of 3923 articles were selected for title and abstract screening. A total of 78 studies were then selected for full-text screening. Of these, 32 targeted COPD and 46 targeted asthma. Full-text screening of the eligibility criteria eventually led to the inclusion of 6 studies targeting COPD and 7 studies targeting asthma. 
Figure 1. PRISMA flowchart describing study identification and selection process. PRISMA: Preferred Reporting Items for Systematic Reviews and Meta-Analyses.
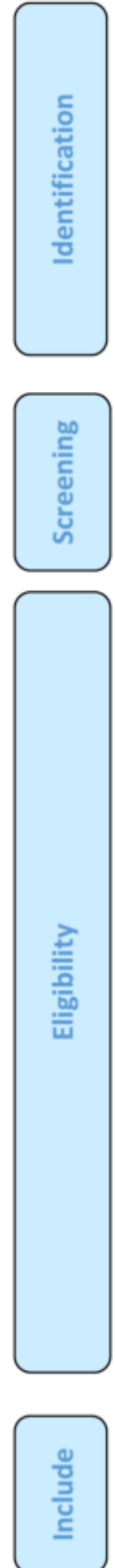

Studies included $(n=7)$
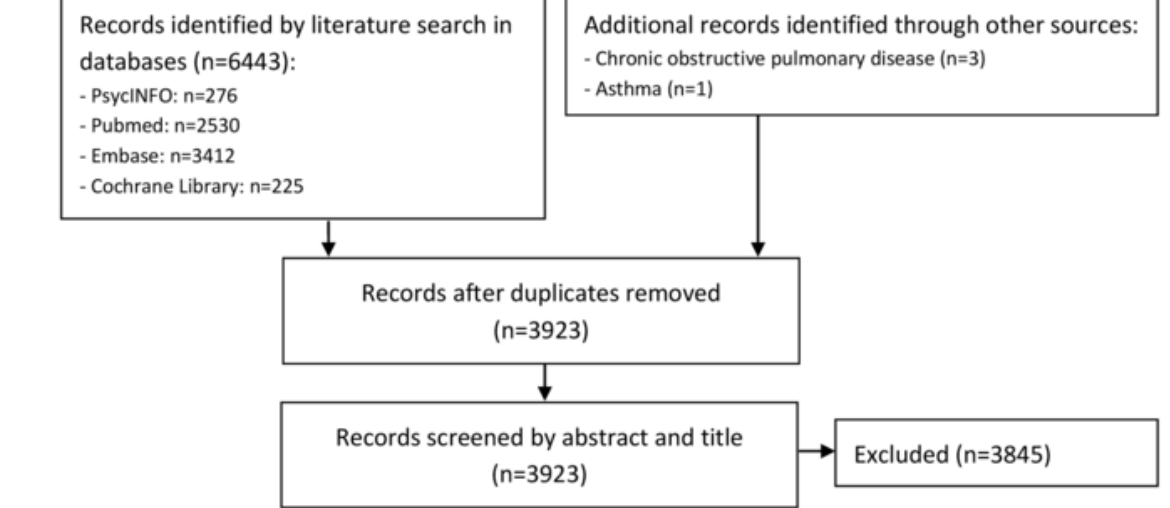

Full-text articles assessed for eligibility ( $n=78$ )

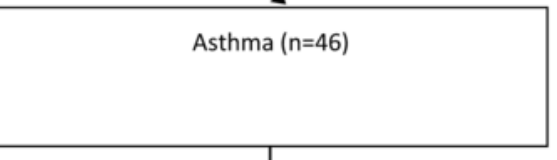
$(n=32)$

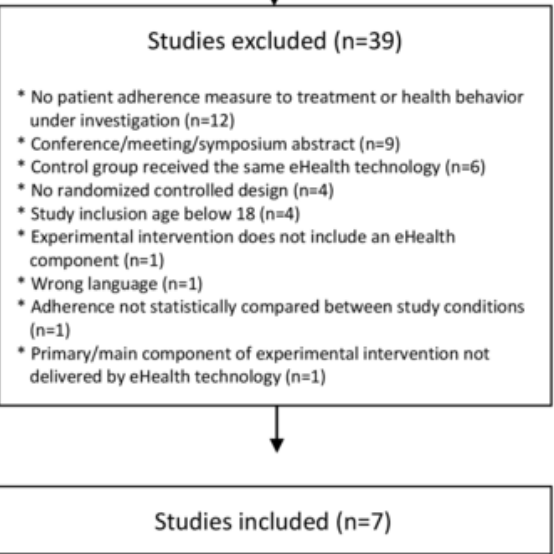

Studies excluded $(n=25)$

- No patient adherence measure to treatment or health behavior under investigation $(\mathrm{n}=5)$

(

- Adherence not statistically compared between study conditions

$(n=3)$

- Conference/meeting/symposium abstract $(n=4)$

* Control group received the same eHealth technology $(n=1)$

Wroplation: only subsample with COPD $(n=2)$

* Experimental intervention does not include an eHealth component

$(n=1)$

* Wrong type of treatment adherence ( $n=77$ )

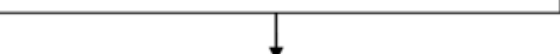

Studies included $(n=6)$

\section{Results for COPD}

\section{Study Characteristics}

Multimedia Appendix 3 provides an overview of study and intervention characteristics; of the six included studies, two interventions were internet-based and four were telephone-based. Interventions involved the telemonitoring of symptoms and adherence, education and counseling (eg, knowledge of the disease, smoking cessation, inhaler techniques), and self-support modules (eg, to help patients identify disease exacerbations or to support psychological well-being). Medication adherence was a primary outcome in three studies and a secondary outcome in three others. The studies were conducted in Europe, China, and New Zealand.

\section{Quality Assessment}

Figure 2 presents the results of the risk-of-bias assessment for each study separately. None of the studies were rated as having low risk of bias on all six dimensions. The majority of studies had a high risk of performance bias $(n=5)$ and detection bias $(n=4)$. These were due to the lack of blinding and participants self-reporting their medication adherence while being aware of their allocated study condition. Studies with a high risk of attrition bias $(n=2)$ generally did not analyze the data according to an intention-to-treat design, thus excluding participants who did not adhere to the intervention or were lost to follow-up. 
Figure 2. Risk of bias analysis on individual studies investigating effectiveness of eHealth interventions on medication adherence in patients with chronic obstructive pulmonary disease.
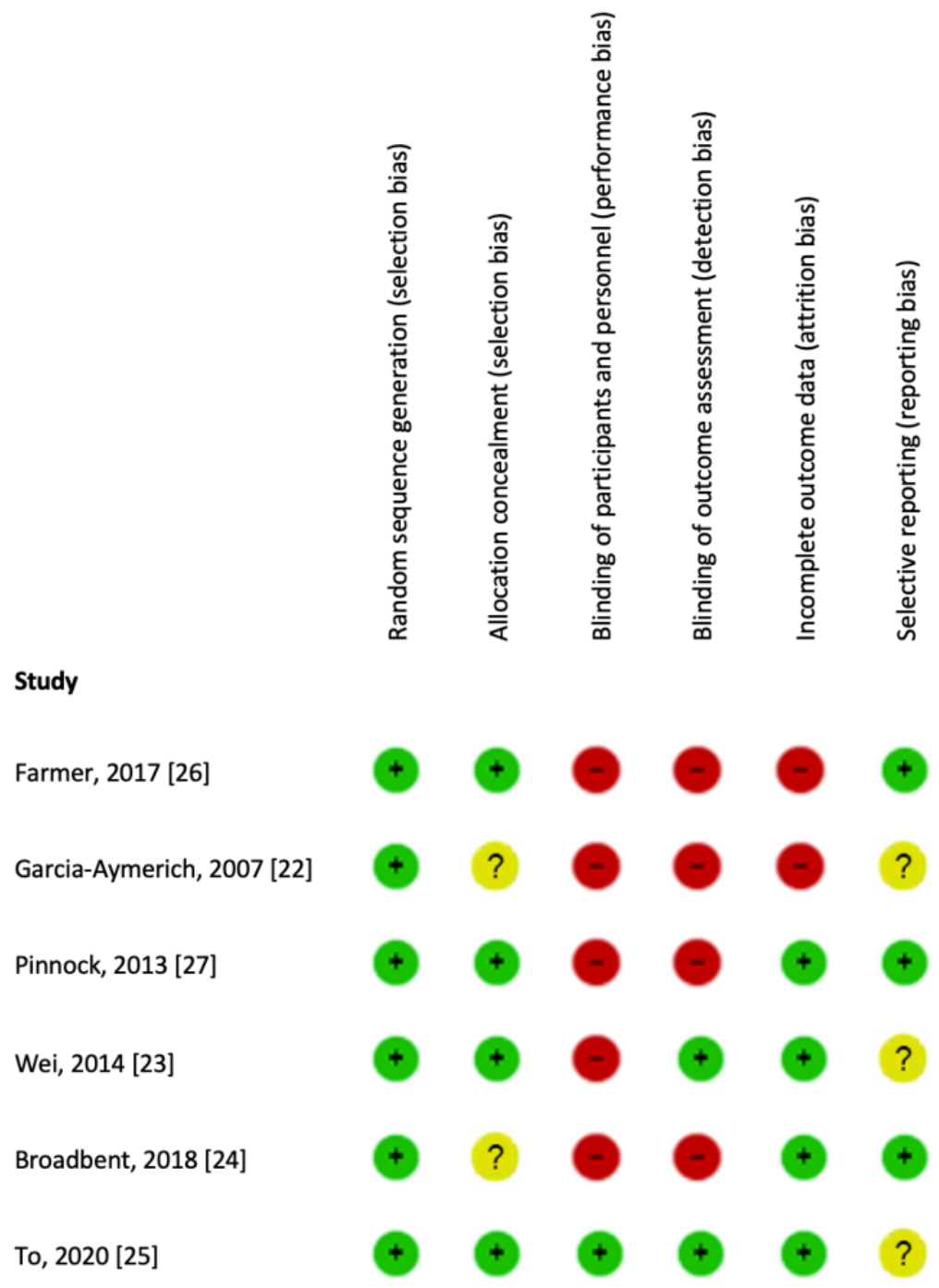

\section{Effects of eHealth Interventions on Medication Adherence}

was operationalized. In one study, telephone-based integrated care resulted in significant effects in terms of the percentages of self-reported medication inhaler adherence and observed correct inhaler maneuvers, whereas no effects were found for the percentages of self-reported oral medication adherence [22]. In another study, telephone-based telemonitoring did not result in significant effects on adherence to the medication regimen, but there were significant effects on the percentages of people adhering at least $80 \%$ to the regimen; in both those operationalizations, adherence was measured objectively by an administration tracker attached to the device [25]. In the last study, telemonitoring and treatment reminders delivered by an internet-linked robot resulted in significant results when medication adherence was measured with a self-reported questionnaire, but nonsignificant results when the percentages of medication adherence were measured objectively by an administration tracker attached to the device [24].

Telephone-based pharmaceutical care including education and counseling was found to be effective as compared to care as usual in terms of adherence operationalized as pill count [23]. The three studies that reported mixed results all investigated the effect of an eHealth intervention as an add-on to care as usual. These studies differed regarding the type of intervention and the technology used, as well as how medication adherence

\section{Results for Asthma}

\section{Study Characteristics}

Multimedia Appendix 3 presents the details on study and intervention characteristics. Of the seven included studies focusing on asthma, six interventions were telephone-based 
[28-33] and one was internet-based [34]. Interventions involved monitoring and management of medication, including reminders for intake and refills, as well as pharmacist consultations. Control conditions included, among others, asthma education, monitoring and treatment by a general practitioner or specialist, and inhaler use tracking. Study periods ranged from 2.5 to 18 months. Overall, five studies included medication adherence as a primary outcome. Most studies were conducted in the United States $(n=4)$.

\section{Quality Assessment}

Figure 3 presents the results of the risk-of-bias assessment. None of the studies were rated as having low risk of bias on all six dimensions. A substantial number of studies had a high risk of performance bias $(n=5)$ or detection bias $(n=3)$, due to the lack of blinding. Most studies also had a high risk of attrition bias $(n=4)$, mainly because they did not analyze the data in an intention-to-treat design.

Figure 3. Risk of bias analysis on individual studies investigating effectiveness of eHealth interventions on medication adherence in patients with asthma.

\section{Study \\ Bender, 2010 [28] \\ Lv, 2012 [29] \\ Rasmussen, 2005 [34] \\ Strandbygaard, $2010[30]$ \\ Vollmer, 2011 [31] \\ Young, 2012 [32] \\ Bender, 2020 [33]}

\section{Effects of eHealth Interventions on Medication Adherence}

The effectiveness of the interventions is displayed in Table 1. We determined that five of the seven included studies on medication adherence in asthma reported significant effects on at least one of the operationalizations of medication adherence compared to control conditions $[28,30,31,33,34]$. However, at the same time, two of these five studies reported nonsignificant effects when other operationalizations of medication adherence were used [30,33]. In addition, two studies reported nonsignificant effects [29,32]. In two studies, a standalone eHealth intervention involving an interactive voice response
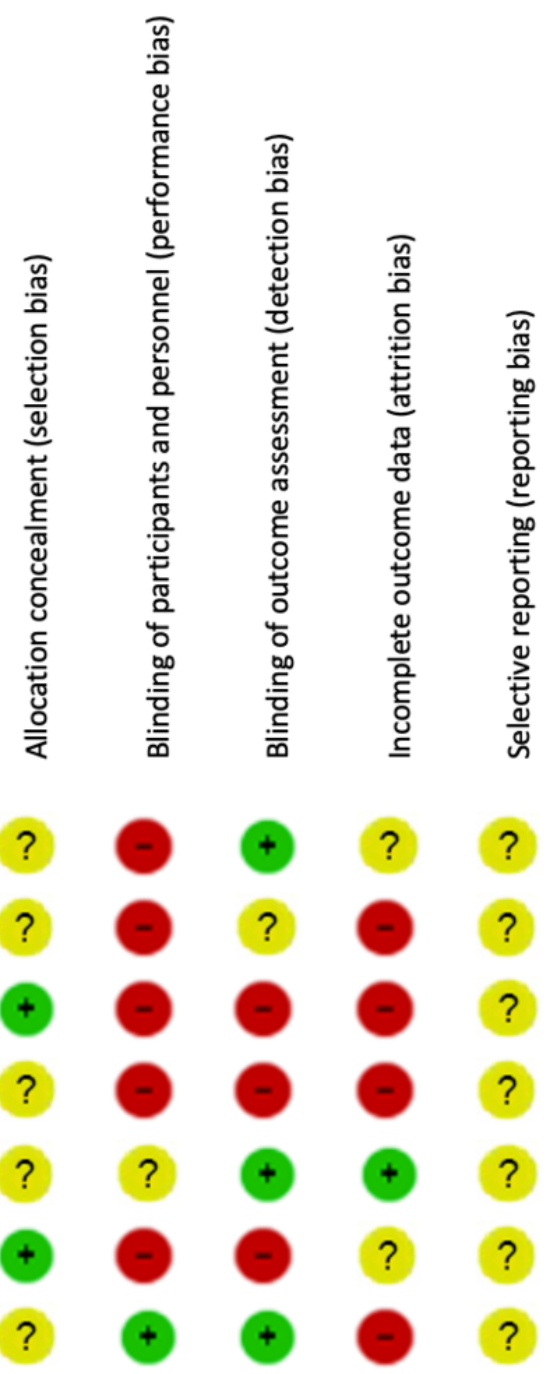

system for monitoring, medication reminders, and education was found to significantly increase self-reported medication adherence [28,31]. One of these studies operationalized medication adherence on the basis of self-report [31], whereas the other tracked inhaler use or assessed inhaler weight [28]. In another study, a guided standalone internet-based monitoring and management tool was found to significantly increase self-reported medication adherence as compared to a control group receiving monitoring and treatment by a general practitioner or specialist [34]. Another study also investigating the effect of SMS text message medication reminders as an add-on to care as usual reported mixed results depending on how adherence was operationalized [30]. Compared to care as 
usual, there was a significant improvement in the percentage of inhaler use, but not in the percentage of participants collecting their medication refills, as recorded in pharmacy reports. Another study also investigated the effect of a standalone monitoring and management support tool, but provided via SMS text message or telephone interactive voice response or via email [33]; the results were mixed depending on the operationalization of medication adherence and the group comparisons. Comparing the combined intervention groups with care as usual, the study found no significant effects on self-reported medication adherence. When the intervention groups were compared, no significant effect was found on self-reported use of reliever medication or on the asthma medication ratio, but a greater increase in self-reported use of controller medication was found in the SMS text message/telephone group as compared to the email group. Telephone-based pharmacist consultations as an add-on to care as usual did not result in a significant increase in self-reported adherence rates compared with care as usual [32]. Lv and colleagues [29] investigated the effect of a standalone eHealth intervention using SMS reminders about asthma management; they reported nonsignificant effects in comparison with care as usual or with verbal or written asthma education. Medication adherence was defined as the percentage of participants that were adherent, although the exact operationalization was unclear. 
Table 1. Effects of eHealth interventions for medication adherence in chronic obstructive pulmonary disease and asthma: study results ${ }^{\mathrm{a}}$.

Condition; reference and study design; Outcome measure and outcome operationalization
Between-group results

$\begin{array}{ll}\text { Between- } & \text { Study quality (num- } \\ \text { group statis- } & \text { ber of dimensions } \\ \text { tic }(P \text { value }) & \text { unclear/low/high } \\ & \text { risk })^{\text {b }}\end{array}$

\section{Chronic obstructive pulmonary disease}

Farmer, 2017 [26], add-on to care as usual

Medication adherence

Medication Adherence Rate Scale

$$
\begin{aligned}
& \text { line to } 12 \text { months. TG: } 0.17 \\
& \text { (2.47) vs CG: } 0.33 \text { (3.65). }
\end{aligned}
$$

Garcia-Aymerich, 2007 [22], add-on to care as usual

Percentage of oral medication Medication Adherence Scale adherence

Percentage of inhaler medica- Inhaler Adherence Scale tion adherence

Percentage of correct inhaler Observed inhaler skills maneuvers

Pinnock, 2013 [27], add-on to care as usual

Medication adherence

Medication Adherence Rate Scale

Wei, 2014 [23], standalone

Percentage of medication adher- Pill count ence

Broadbent, 2018 [24], add-on to care as usual

Percentage of medication adher- Administration tracker on device ence

Medication adherence

Medication Adherence Rate Scale

To, 2020 [25], add-on to care as usual

Medication regimen adherence

Ratio number of doses taken (administration tracker) / number of doses prescribed

Percentage of $\geq 80 \%$ adherence

Ratio number of doses taken (administration tracker)/number of doses prescribed

Correct inhaler technique

Inhaler use checklist

\section{Asthma}

Bender, 2010 [28], standalone

Percentage of inhaled corticos- Electronic tracking device taken puff/number of prescribed puffs)

\section{Lv, 2012 [29], add-on to care as usual}

Percentage of adherers

Not specified CG: $85 \%$ CG: $37 \%$ CG: $24 \%$

12-month results. TG: 24.0 (1.7) vs CG: 23.7 (1.9)

12-month results. TG: 66.5 (8.6) vs CG: 54.4 (12.5)

TG: $48.5 \%$ vs CG: $29.5 \%$ line to 4 months. TG: 1.63 (0.56) vs CG: 0.12 (0.55)

2-month results. TG: 99.8

(15.0) vs CG: 92.7 (30.0)

2-month results. TG: 85.7 vs

CG: 71.4 vs CG: 79.9 (17.1) (16.8) teroids adherence (number of

12-month results. TG: $90 \%$ vs

12-month results. TG: $71 \%$ vs

12-month results. TG: $86 \%$ vs

Difference in score from base.06

.12

2-month results. TG: 91.9 (7.8)

CG: 64.5 (17.2) vs TG: $49.1 \quad .003$

TG: 80 vs CG1: 74.1 vs CG2: .11 50

Rasmussen, 2005 [34], standalone

Self-reported as almost always tak- TG: 87 vs CG2: 54

Percentage of inhaled corticosteroids adherers ing inhaled corticosteroids

Self-reported as almost always tak- CG1: 79 vs CG2: 54
Percentage of inhaled corticosteroids adherers ing inhaled corticosteroids 


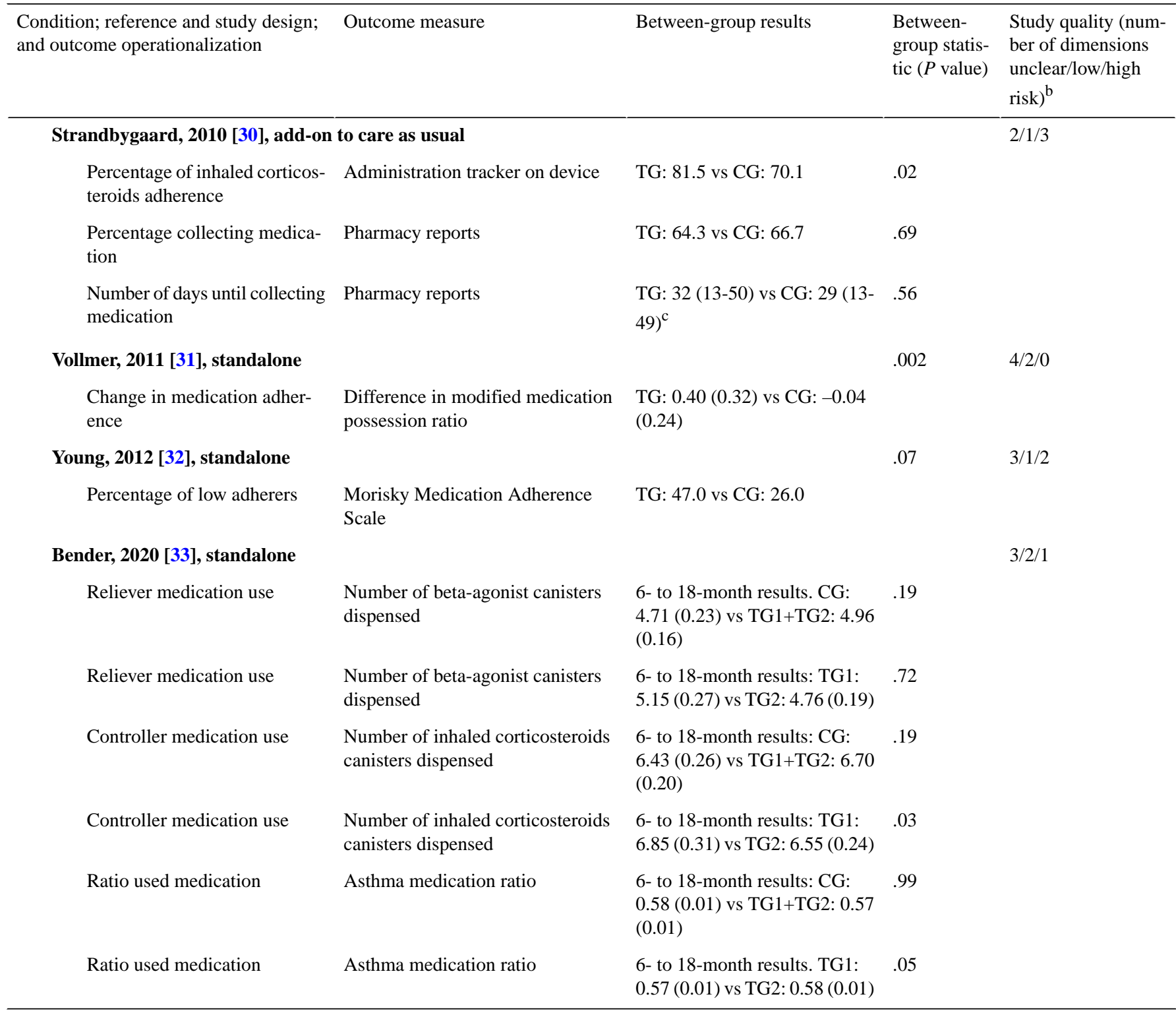

${ }^{\mathrm{a}} \mathrm{CG}$ : control group; TG: treatment group.

${ }^{b}$ Risk of bias according to six dimensions of the Cochrane Collaboration's risk of bias tool.

${ }^{\mathrm{c}}$ Values represent means (ranges).

\section{Discussion}

\section{General Discussion}

This review investigated the effects of eHealth interventions in improving adherence to medication treatment by patients with COPD or asthma. In general, mixed results were found and no definite conclusions could be drawn.

The mixed results of the current review may be explained by differences in study design, type and intensity of eHealth interventions, type of control condition, and assessment and operationalization of outcome measures. Previous reviews and meta-analyses have demonstrated small but significant effects of eHealth interventions in improving medication adherence for patients with asthma $[18,19]$, as well as for more diverse populations of chronically ill patients [13] and individuals with long-term medication [35]. The latter two studies found positive effects in $66 \%$ and $59 \%$ of the studies, respectively. In line with our rather inconclusive and mixed findings, all of the abovementioned overview studies highlighted the considerable amount of heterogeneity among study designs and outcomes, and the limited number of high-quality studies conducted.

Differences in operationalization may have contributed to the discrepant results, in that self-report questionnaires such as the MARS [36] might be less sensitive in detecting actual changes in treatment adherence than more direct adherence assessments such as pill counts or inhaler use tracking devices. Indeed, such variations in objective and subjective measurements of medication adherence have been widely reported in the literature $[37,38]$. To the best of our knowledge, this is the first systematic review to investigate the effects of eHealth interventions on medication adherence in adult patients with COPD or asthma. Our findings are limited by the small number of included studies and considerable heterogeneity regarding different study aspects. This challenges the interpretation of eHealth intervention effects 
in terms of medication adherence for patients with asthma and COPD.

\section{Future Research Directions and Recommendations}

Given the limited number of high-quality studies, more studies that minimize potential bias risks are needed to create a more substantial and reliable body of research on the effectiveness of eHealth interventions to improve treatment adherence in COPD and asthma. Furthermore, as a wide variety of outcome measures have been used, future studies could benefit from standardizing measures with respect to adherence outcome. In addition, standardizing the operationalizations of such outcome measures and reporting effect sizes instead of mere statistics in terms of significance could potentially lead to more clear-cut results. Future research would benefit from studies with sufficient statistical power. This would also allow for subgroup analyses, which could provide more insight into what types, intensities, and components of interventions might be more effective for different subgroups, ultimately leading to more personalized or tailor-made treatments. Preliminary research suggests that increased adherence can improve patient outcomes as well as reduce health care costs [5,39]. However, more research is needed to elucidate the cost- effectiveness of eHealth interventions targeting adherence in comparison to usual care. Finally, future studies of eHealth interventions should therefore incorporate cost-effectiveness analyses to elucidate effects in relation to costs as compared with usual care.

\section{Conclusion}

No firm conclusion can be drawn due to the small numbers of studies and their heterogeneous results. Much remains to be learned about the potential of eHealth in optimizing treatment adherence in COPD and asthma-for example, in terms of what types and intensities of eHealth intervention components are effective for what types of individuals.

\section{Acknowledgments}

This study was funded by the Dutch National Health Care Institute. The funder was not involved in carrying out the research activities. We would like to thank Caroline Planting for her help in conducting the literature search.

\section{Conflicts of Interest}

None declared.

\section{Multimedia Appendix 1}

PRISMA 2020 checklist.

[DOCX File, 32 KB-Multimedia Appendix 1]

\section{Multimedia Appendix 2}

Search string.

[DOCX File, $21 \mathrm{~KB}-\underline{\text { Multimedia Appendix 2] }}$

\section{Multimedia Appendix 3}

Study and intervention characteristics.

[DOCX File, 20 KB-Multimedia Appendix 3]

\section{References}

1. GBD 2017 Disease and Injury Incidence Prevalence Collaborators. Global, regional, and national incidence, prevalence, and years lived with disability for 354 diseases and injuries for 195 countries and territories, 1990-2017: a systematic analysis for the Global Burden of Disease Study 2017. Lancet 2018 Dec 10;392(10159):1789-1858 [FREE Full text] [doi: 10.1016/S0140-6736(18)32279-7] [Medline: 30496104]

2. Shin S, Bai L, Burnett RT, Kwong JC, Hystad P, van Donkelaar A, et al. Air Pollution as a Risk Factor for Incident Chronic Obstructive Pulmonary Disease and Asthma. A 15-Year Population-based Cohort Study. Am J Respir Crit Care Med 2021 May 01;203(9):1138-1148. [doi: 10.1164/rccm.201909-1744oc]

3. GBD 2015 Chronic Respiratory Disease Collaborators. Global, regional, and national deaths, prevalence, disability-adjusted life years, and years lived with disability for chronic obstructive pulmonary disease and asthma, 1990-2015: a systematic analysis for the Global Burden of Disease Study 2015. Lancet Respir Med 2017 Sep;5(9):691-706 [FREE Full text] [doi: 10.1016/S2213-2600(17)30293-X] [Medline: 28822787]

4. Vrijens B, Dima AL, Van Ganse E, van Boven JF, Eakin MN, Foster JM, et al. What We Mean When We Talk About Adherence in Respiratory Medicine. J Allergy Clin Immunol Pract 2016 Sep;4(5):802-812 [FREE Full text] [doi: 10.1016/j.jaip.2016.05.019] [Medline: 27587314]

5. Mäkelä MJ, Backer V, Hedegaard M, Larsson K. Adherence to inhaled therapies, health outcomes and costs in patients with asthma and COPD. Respir Med 2013 Oct;107(10):1481-1490 [FREE Full text] [doi: 10.1016/j.rmed.2013.04.005] [Medline: 23643487] 
6. van Boven JFM, Chavannes NH, van der Molen T, Rutten-van Mölken MPMH, Postma MJ, Vegter S. Clinical and economic impact of non-adherence in COPD: a systematic review. Respir Med 2014 Jan;108(1):103-113 [FREE Full text] [doi: 10.1016/j.rmed.2013.08.044] [Medline: 24070566]

7. Kaye L, Theye B, Smeenk I, Gondalia R, Barrett MA, Stempel DA. Changes in medication adherence among patients with asthma and COPD during the COVID-19 pandemic. J Allergy Clin Immunol Pract 2020 Jul;8(7):2384-2385 [FREE Full text] [doi: 10.1016/j.jaip.2020.04.053] [Medline: 32371047]

8. Bårnes CB, Ulrik CS. Asthma and adherence to inhaled corticosteroids: Current status and future perspectives. Respir Care 2015 Mar 12;60(3):455-468 [FREE Full text] [doi: 10.4187/respcare.03200] [Medline: 25118311]

9. Ingebrigtsen TS, Marott JL, Nordestgaard BG, Lange P, Hallas J, Dahl M, et al. Low use and adherence to maintenance medication in chronic obstructive pulmonary disease in the general population. J Gen Intern Med 2015 Jan 23;30(1):51-59 [FREE Full text] [doi: 10.1007/s11606-014-3029-0] [Medline: 25245885]

10. George M, Bender B. New insights to improve treatment adherence in asthma and COPD. PPA 2019 Jul; Volume 13:1325-1334. [doi: 10.2147/ppa.s209532]

11. Normansell R, Kew K, Stovold E. Interventions to improve adherence to inhaled steroids for asthma. Cochrane Database Syst Rev 2017 Apr 18;4(4):CD012226 [FREE Full text] [doi: 10.1002/14651858.CD012226.pub2] [Medline: 28417456]

12. Bryant J, McDonald V, Boyes A, Sanson-Fisher R, Paul C, Melville J. Improving medication adherence in chronic obstructive pulmonary disease: a systematic review. Respir Res 2013 Oct 20;14(1):109 [FREE Full text] [doi: 10.1186/1465-9921-14-109] [Medline: 24138097]

13. Anglada-Martinez H, Riu-Viladoms G, Martin-Conde M, Rovira-Illamola M, Sotoca-Momblona JM, Codina-Jane C. Does mHealth increase adherence to medication? Results of a systematic review. Int J Clin Pract 2015 Jan;69(1):9-32. [doi: 10.1111/ijcp.12582] [Medline: 25472682]

14. Hamine S, Gerth-Guyette E, Faulx D, Green BB, Ginsburg AS. Impact of mHealth chronic disease management on treatment adherence and patient outcomes: A systematic review. J Med Internet Res 2015 Feb 24;17(2):e52 [FREE Full text] [doi: 10.2196/jmir.3951] [Medline: 25803266]

15. Tao D, Xie L, Wang T, Wang T. A meta-analysis of the use of electronic reminders for patient adherence to medication in chronic disease care. J Telemed Telecare 2014 Aug 21;21(1):3-13. [doi: 10.1177/1357633x14541041]

16. Thakkar J, Kurup R, Laba T, Santo K, Thiagalingam A, Rodgers A, et al. Mobile Telephone Text Messaging for Medication Adherence in Chronic Disease: A Meta-analysis. JAMA Intern Med 2016 Mar 1;176(3):340-349. [doi:

10.1001/jamainternmed.2015.7667] [Medline: 26831740]

17. Kini V, Ho PM. Interventions to Improve Medication Adherence: A Review. JAMA 2018 Dec 18;320(23):2461-2473. [doi: 10.1001/jama.2018.19271] [Medline: 30561486]

18. Bonini M. Electronic health (e-Health): emerging role in asthma. Curr Opin Pulm Med 2017 Jan;23(1):21-26. [doi: 10.1097/MCP.0000000000000336] [Medline: 27763999]

19. Jeminiwa R, Hohmann L, Qian J, Garza K, Hansen R, Fox BI. Impact of eHealth on medication adherence among patients with asthma: A systematic review and meta-analysis. Respir Med 2019 Mar;149:59-68 [FREE Full text] [doi: 10.1016/j.rmed.2019.02.011] [Medline: $\underline{\text { 30803887] }}$

20. Aardoom JJ, Loheide-Niesmann L, Ossebaard HC, Riper H. Effectiveness of eHealth Interventions in Improving Treatment Adherence for Adults With Obstructive Sleep Apnea: Meta-Analytic Review. J Med Internet Res 2020 Feb 18;22(2):e16972 [FREE Full text] [doi: 10.2196/16972] [Medline: 32130137]

21. Higgins J, Green S. Cochrane Handbook for Systematic Reviews of Interventions (Version 5.1.0). 2011. URL: https:/ /handbook-5-1.cochrane.org/ [accessed 2021-07-16]

22. Garcia-Aymerich J, Hernandez C, Alonso A, Casas A, Rodriguez-Roisin R, Anto JM, et al. Effects of an integrated care intervention on risk factors of COPD readmission. Respir Med 2007 Jul;101(7):1462-1469 [FREE Full text] [doi: 10.1016/j.rmed.2007.01.012] [Medline: 17339106]

23. Wei L, Yang X, Li J, Liu L, Luo H, Zheng Z, et al. Effect of pharmaceutical care on medication adherence and hospital admission in patients with chronic obstructive pulmonary disease (COPD): a randomized controlled study. J Thorac Dis 2014 Jun;6(6):656-662 [FREE Full text] [doi: 10.3978/j.issn.2072-1439.2014.06.20] [Medline: 24976987]

24. Broadbent E, Garrett J, Jepsen N, Li Ogilvie V, Ahn HS, Robinson H, et al. Using Robots at Home to Support Patients With Chronic Obstructive Pulmonary Disease: Pilot Randomized Controlled Trial. J Med Internet Res 2018 Feb 13;20(2):e45 [FREE Full text] [doi: 10.2196/jmir.8640] [Medline: 29439942]

25. To KW, Lee IF, Choi KC, Cheung YTY, Yu DSF. An information-motivation-behavioural-based model and adherence to inhalation therapy and other health outcomes in patients with chronic obstructive pulmonary disease: A pilot randomized controlled trial. Int J Nurs Pract 2020 Apr;26(2):e12799. [doi: 10.1111/ijn.12799] [Medline: 31903654]

26. Farmer A, Williams V, Velardo C, Shah SA, Yu L, Rutter H, et al. Self-Management Support Using a Digital Health System Compared With Usual Care for Chronic Obstructive Pulmonary Disease: Randomized Controlled Trial. J Med Internet Res 2017 May 03;19(5):e144 [FREE Full text] [doi: 10.2196/jmir.7116] [Medline: 28468749]

27. Pinnock H, Hanley J, McCloughan L, Todd A, Krishan A, Lewis S, et al. Effectiveness of telemonitoring integrated into existing clinical services on hospital admission for exacerbation of chronic obstructive pulmonary disease: researcher blind, 
multicentre, randomised controlled trial. BMJ 2013 Oct 17;347:f6070 [FREE Full text] [doi: 10.1136/bmj.f6070] [Medline: 24136634]

28. Bender BG, Apter A, Bogen DK, Dickinson P, Fisher L, Wamboldt FS, et al. Test of an interactive voice response intervention to improve adherence to controller medications in adults with asthma. J Am Board Fam Med 2010 Mar 05;23(2):159-165 [FREE Full text] [doi: 10.3122/jabfm.2010.02.090112] [Medline: 20207925]

29. Lv Y, Zhao H, Liang Z, Dong H, Liu L, Zhang D, et al. A mobile phone short message service improves perceived control of asthma: a randomized controlled trial. Telemed J E Health 2012 Jul;18(6):420-426. [doi: 10.1089/tmj.2011.0218] [Medline: 22667695]

30. Strandbygaard U, Thomsen SF, Backer V. A daily SMS reminder increases adherence to asthma treatment: a three-month follow-up study. Respir Med 2010 Feb;104(2):166-171 [FREE Full text] [doi: 10.1016/j.rmed.2009.10.003] [Medline: 19854632]

31. Vollmer W, Feldstein A, Smith D, Dubanoski J, Waterbury A, Schneider J, et al. Use of health information technology to improve medication adherence. Am J Manag Care 2011 Dec;17(12 Spec No):SP79-SP87 [FREE Full text] [Medline: 22216772]

32. Young HN, Havican SN, Griesbach S, Thorpe JM, Chewning BA, Sorkness CA. Patient and phaRmacist telephonic encounters (PARTE) in an underserved rural patient population with asthma: results of a pilot study. Telemed J E Health 2012;18(6):427-433 [FREE Full text] [doi: 10.1089/tmj.2011.0194] [Medline: 22656403]

33. Bender BG, Wagner NM, Shoup JA, Goodrich GK, Shetterly SM, Cvietusa PJ, et al. Adults With Asthma Experience No Increase in Asthma-related Exacerbations When Digital Communication Technology Tools Are Employed to Offset Provider Workload: A Pragmatic Randomized Trial. Med Care 2020;58(4):352-359. [doi: 10.1097/MLR.0000000000001265] [Medline: 32197029]

34. Rasmussen LM, Phanareth K, Nolte H, Backer V. Internet-based monitoring of asthma: a long-term, randomized clinical study of 300 asthmatic subjects. J Allergy Clin Immunol 2005 Jun;115(6):1137-1142. [doi: 10.1016/j.jaci.2005.03.030] [Medline: 15940125]

35. Pouls BPH, Vriezekolk JE, Bekker CL, Linn AJ, van Onzenoort HAW, Vervloet M, et al. Effect of Interactive eHealth Interventions on Improving Medication Adherence in Adults With Long-Term Medication: Systematic Review. J Med Internet Res 2021 Jan 08;23(1):e18901 [FREE Full text] [doi: 10.2196/18901] [Medline: 33416501]

36. Thompson K, Kulkarni J, Sergejew A. Reliability and validity of a new Medication Adherence Rating Scale (MARS) for the psychoses. Schizophrenia Research 2000 May;42(3):241-247. [doi: 10.1016/s0920-9964(99)00130-9]

37. Van Steenis MNA, Driesenaar JA, Bensing JM, Van Hulten R, Souverein PC, Van Dijk L, et al. Relationship between medication beliefs, self-reported and refill adherence, and symptoms in patients with asthma using inhaled corticosteroids. Patient Prefer Adherence 2014 Jan;8:83-91 [FREE Full text] [doi: 10.2147/PPA.S44185] [Medline: 24470757]

38. Lam WY, Fresco P. Medication Adherence Measures: An Overview. Biomed Res Int 2015;2015:217047 [FREE Full text] [doi: 10.1155/2015/217047] [Medline: 26539470]

39. Sokol MC, McGuigan KA, Verbrugge RR, Epstein RS. Impact of medication adherence on hospitalization risk and healthcare cost. Med Care 2005 Jun;43(6):521-530. [doi: 10.1097/01.mlr.0000163641.86870.af] [Medline: 15908846]

\author{
Abbreviations \\ COPD: chronic obstructive pulmonary disease \\ ICS: inhaled corticosteroids \\ MARS: Medication Adherence Rating Scale \\ OSA: obstructive sleep apnea \\ PRISMA: Preferred Reporting Items for Systematic Reviews and Meta-Analyses
}

Edited by G Eysenbach; submitted 08.04.21; peer-reviewed by B Pouls, I Yang; comments to author 27.04.21; revised version received
12.06.21; accepted 14.06.21; published 27.07.21
Please cite as:
Schulte MHJ, Aardoom JJ, Loheide-Niesmann L, Verstraete LLL, Ossebaard HC, Riper H
Effectiveness of eHealth Interventions in Improving Medication Adherence for Patients With Chronic Obstructive Pulmonary Disease
or Asthma: Systematic Review
J Med Internet Res 2021;23(7):e29475
URL: $\underline{\text { https://www.jmir.org/2021/7/e29475 }}$
doi: $\underline{10.2196 / 29475}$
PMID: $\underline{34313593}$


CMieke H J Schulte, Jiska J Aardoom, Lisa Loheide-Niesmann, Leonie L L Verstraete, Hans C Ossebaard, Heleen Riper. Originally published in the Journal of Medical Internet Research (https://www.jmir.org), 27.07.2021. This is an open-access article distributed under the terms of the Creative Commons Attribution License (https://creativecommons.org/licenses/by/4.0/), which permits unrestricted use, distribution, and reproduction in any medium, provided the original work, first published in the Journal of Medical Internet Research, is properly cited. The complete bibliographic information, a link to the original publication on https://www.jmir.org/, as well as this copyright and license information must be included. 